\title{
Impact of Tunnel Temperature Variations on Surrounding Rocks in Cold Regions
}

\author{
Qingyang Yu' ${ }^{1,2}$, Chao Zhang ${ }^{1}$, Zhenxue Dai ${ }^{1,2^{*}}$, Chao Du' ${ }^{1}$ Mohamad Reza Soltanian ${ }^{1,3}$, \\ Mojtaba Soltanian ${ }^{*}$ \\ ${ }^{1}$ College of Construction Engineering, Jilin University, \\ Changchun, 130026, China \\ 2 Engineering Research Centre of Geothermal Resources Development Technology and Equipment, Ministry of Education, \\ Jilin University, Changchun, 130026, China \\ ${ }^{3}$ Department of Geology, \\ University of Cincinnati, USA \\ ${ }^{4}$ Department of Mechanical Engineering, \\ University of Kerman, Kerman, Iran \\ *Corresponding author, e-mail: dzx@jlu.edu.cn
}

Received: 10 September 2018, Accepted: 12 December 2018, Published online: 14 January 2019

\begin{abstract}
Temperature is an important factor in designing and maintaining tunnels, especially in cold regions. We present three-dimensional numerical simulations of tunnel temperature fields at different temperature conditions. We study the tunnel temperature field in two different conditions with relatively low and high ambient temperatures representing winter and summer of northeast China. We specifically study how these temperature conditions affect tunnel temperature and its migration to surrounding rocks. We show how placing an insulation layer could affect the temperature distribution within and around tunnels. Our results show that the temperature field without using an insulation layer is closer to the air temperature in the tunnel, and that the insulation layer has shielding effects and could plays an important role in preventing temperature migration to surrounding rocks. We further analyzed how thermal conductivity and thickness of insulation layer control the temperature distribution. The thermal conductivity and thickness of insulation layer only affect the temperature of the surrounding rocks which are located at distances below $\sim 20 \mathrm{~m}$ from the lining.
\end{abstract}

\section{Keywords}

tunnel, temperature field, numerical simulation, insulation layer

\section{Introduction}

Temperature is an important factor to consider in designing and maintaining tunnels specially in cold regions. For example, the frozen damage is destructive to tunnels built in cold regions due to dramatic changes in temperature [1]. The damage includes cracks, water leakage through the lining, and scrap of the main structures [2]. These destructive problems could potentially affect use and maintenance of tunnels. Therefore, understanding tunnel temperature field is critical. The temperature distribution within tunnel lining and the surrounding rocks is also essential for the analysis of stress and freeze-thaw effect. The changes in ambient temperature result in temperature changes for the tunnel lining and the surrounding rock. Numerical simulations are useful tools to enhance our understanding of temperature distribution within and around tunnels. In this paper, we perform three-dimensional (3D) finite element (FE) simulations of tunnel temperature field in relatively hot and cold seasons.

Several studies have been conducted to understand the tunnel temperature field. They include field monitoring [3-8], analytical methods [9-16], and numerical simulations [17-22]. We briefly review some important prior work.

Field studies. Lai [3] measured the temperature field inside and outside of a tunnel in a cold region. Their results provide basis for antifreeze insulation and design of operating ventilation. Chen [4] evaluated the effect of antifreeze thermal insulating materials on tunnel temperature fields. Li et al. [5] used an autonomous recording system to understand the lining surface temperature of the Hongfu tunnel on hourly basis for about two years. They 
found that the temperature change was nearly sinusoidal. Chen et al. [6] tested the temperature by eleven sections of a highway tunnel in a cold region. Variation of yearly temperature in tunnel was periodical and nearly followed a sine curve. Ryu et al. [7] investigated behavior and performance of concrete pavement in tunnel using temperature data. They found that the temperature change in tunnels was less than ambient temperature, and it was also more stable. Zhang et al. [8] experimentally investigated the heat transfer performance of tunnel lining ground heat exchangers and its impact including the flow rate, inlet water temperature, and pipe distance.

Analytical methods. Sutoh et al. [9-11] proposed a model that approximate yearly periodic changes of atmospheric temperature in tunnels. Kawamura et al. [12] presented a theory for estimating temperature in tunnels by considering heat convection/conduction between the tunnel ground and air in the tunnel. Their model results reasonably represented the field measured tunnel temperature. Lee et al. [13] presented a method to estimate temperature-dependent thermal conductivity by using solution of inverse heat conduction problem. Luo et al. [14] presented a calculation method using the meteorological observation data to calculate the temperature of the tunnel portal based on the Kriging method. Wang et al. [15] presented a stochastic method for the uncertain temperature characteristics of tunnel which considers boundary conditions as a stochastic process and the rock properties as random variables. They found that the temperature of surrounding rock behaved stochastically, and it affected the thermal stability of the tunnel. Nguyen et al. [16] derived an analytical solution to understand the impact of ice formation on the surrounding rock. They considered the coupling between liquid water and ice crystal under thermodynamic equilibrium, liquid water transport, thermal conduction, and elastic properties of the phases. They found that the hydraulic and thermal diffusivity coefficients are the most important factors to consider. In studied above, specifically Sutoh et al. [9-11], Kawamura et al. [12], and Lee et al. [13] used theories to estimate only tunnel temperature. Luo et al. [14] and Wang et al. [15] presented statistical method to analyze the tunnel temperature. Nguyen et al. [16] mainly considered impact of the liquid water and ice.

Numerical simulations. Lai et al. [17] used a 3D model for simulating temperature fields in ventilated embankments in a cold region. Tan et al. [18, 19] presented a method in terms of the three-zone theory including frozen zone, freezing zone, and an unfrozen zone. The model was used to discuss the effect of insulation material of a tunnel in Tibet region. Lai et al. [20] used the FE package to analyze heat insulation effect of separate lining. Their results show that the temperature of lining and rock decreases gradually by decreasing ventilation temperature and that the maximum temperature difference occurred in a closed air layer. Zhou et al. [21] developed a model to study the heat convection between the air and the tunnel wall, as well as the heat transfer in the surrounding rock and at interfaces between different materials in the structure of the tunnel. They found that mechanical ventilation winds during operation and train-induced winds significantly influence the temperature field distribution in the tunnel. Li et al. [22] built a coupled heat-water model for the tunnel in cold regions based on energy and mass conservation principles. They determined the optimal thickness of the thermal insulation layer by a series of coupled heat-water simulations.

This paper is organized as follows: Section 2 presents our numerical models. Section 3 presents site description and input parameters for our numerical models. In Section 4 we discuss the test results of tunnel temperature fields. In Section 5 we present our sensitivity analysis results to insulation layer parameters. Finally, Section 6 highlights conclusions of this work.

\section{Numerical model}

We developed 3D numerical models to better understand how ambient temperature affect temperature distribution within the tunnel and in the surrounding rock. The temperature transfers in the air, lining, and surrounding rock are calculated based on the general temperature conduction equation with the heat flux, $q\left[\mathrm{~W} / \mathrm{m}^{2}\right]$, as [1]:

$q=-k \frac{d T}{d x}$

where $k$ is the thermal conductivity $\left[\mathrm{W} / \mathrm{m} \cdot{ }^{\circ} \mathrm{C}\right]$, and $d T / d x$ is the temperature gradient. Using the heat convection coeffi-

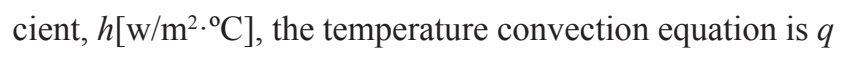
$=h\left(T_{S}-T_{B}\right)$ where $T_{S}$ is surface temperature of lining and rock, and $T_{B}$ is temperature of ambient. Finally, the governing equation for heat transfer which we solve for is as follows:

$$
\frac{\partial}{\partial \boldsymbol{x}}\left(\boldsymbol{k}_{x x} \frac{\partial \boldsymbol{T}}{\partial \boldsymbol{x}}\right)+\frac{\partial}{\partial \boldsymbol{y}}\left(\boldsymbol{k}_{y y} \frac{\partial \boldsymbol{T}}{\partial \boldsymbol{y}}\right)+\frac{\partial}{\partial \boldsymbol{z}}\left(\boldsymbol{k}_{z z} \frac{\partial \boldsymbol{T}}{\partial \boldsymbol{z}}\right)+\dddot{\boldsymbol{q}}=\dot{A} \boldsymbol{c} \frac{\boldsymbol{d} \boldsymbol{T}}{\boldsymbol{d} \boldsymbol{t}}
$$

where $k_{x x}, k_{y y}$, and $k_{z z}$ are the thermal conductivity in $x, y$, and $z$ directions, respectively, $\partial T / \partial x, \partial T / \partial y, \partial T / \partial z$ are thermal gradient along $x, y$, and $z$ directions, respectively, $\dddot{\boldsymbol{q}}[\mathrm{J}]$ 
is internal heat, $\rho\left[\mathrm{kg} / \mathrm{m}^{3}\right]$ is the rock density, and $c\left[\mathrm{~J} / \mathrm{kg} \cdot{ }^{\circ} \mathrm{C}\right]$ is specific heat capacity. The FE formulation of Eq. (2) results in the following systems of equations is as follow:

$[\boldsymbol{C}]\{\dot{\boldsymbol{T}}\}+[\boldsymbol{K}]\{\boldsymbol{T}\}=\{\boldsymbol{Q}\}$,

where $C$ is specific heat capacity matrix, $K$ is thermal conductivity matrix, $\dot{T}$ is derivative of temperature, $T$ is temperature (unknown), and $Q$ is heat flux. In this work, we only focus on a steady-state solution of the governing equations above, and only focus on how changing the boundary conditions for ambient temperatures in summer and winter affects temperature penetration in surrounding rocks.

In this paper, we choose our model parameters using data obtained in Huitougou tunnel located in the northeast China (see Section 3 for more detail). The model geometry is shown in Fig. 1a. The tunnel width is $10 \mathrm{~m}$ with the overburden depth of $15 \mathrm{~m}$. The length, width, and height of the computational domain are $65 \mathrm{~m}, 90 \mathrm{~m}$, and $100 \mathrm{~m}$, respectively (see Fig. 1a). The model extension was chosen based on sensitivity simulations to make sure that there is no boundary effect. We also performed simulations by placing an insulation layer with $5 \mathrm{~cm}$ thickness (see Fig. 1b). The lining thickness is $80 \mathrm{~cm}$. Inside the tunnel is filled with air. A cross-section of the numerical grid is also shown in Fig. 1b. We used 89,500 hexahedral elements with 375,023 nodes.

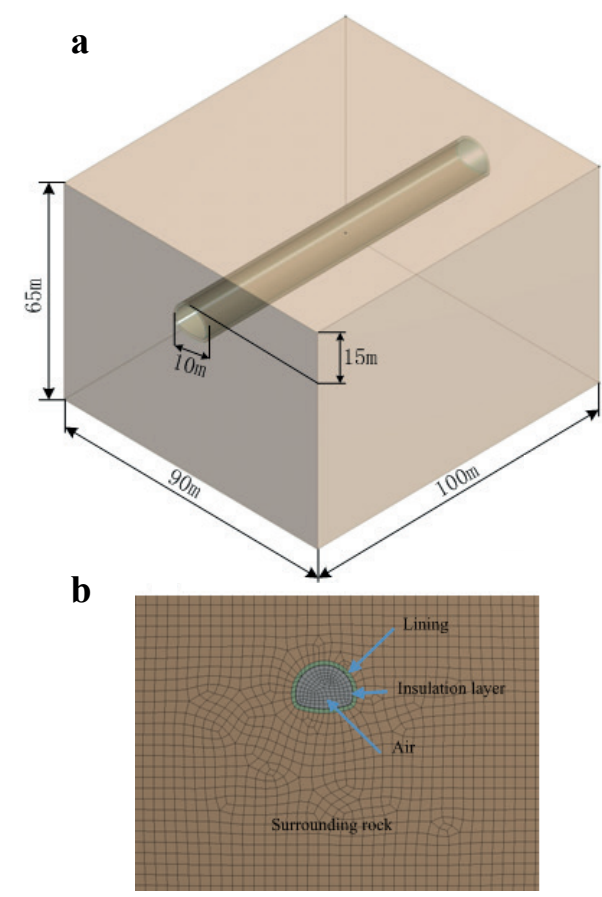

Fig. 1 (a) Model geometry, and (b) a cross-section of the mesh in the middle of the domain. The locations of insulation layer and the lining are clear.
Table 1 Material parameters of tunnel temperature field (extracted from Yufu [23]).

\begin{tabular}{lccc}
\hline Material & $\begin{array}{c}\text { Thermal } \\
\text { conductivity } \\
\left(\mathrm{W} / \mathrm{m} \cdot{ }^{\circ} \mathrm{C}\right)\end{array}$ & $\begin{array}{c}\text { Specific } \\
\text { capacity } \\
\left(\mathrm{J} / \mathrm{kg} \cdot{ }^{\circ} \mathrm{C}\right)\end{array}$ & $\begin{array}{c}\text { Heat density } \\
\left(\mathrm{kg} / \mathrm{m}^{3}\right)\end{array}$ \\
\hline $\begin{array}{l}\text { Surrounding } \\
\text { rock }\end{array}$ & 3.35 & 1080 & 2030 \\
$\begin{array}{l}\text { Lining } \\
\begin{array}{l}\text { Insulation } \\
\text { layer }\end{array}\end{array}$ & 2.4 & 853.5 & 2400 \\
Air & 0.02 & 1789 & 55 \\
\hline
\end{tabular}

\section{Site description and input parameters for the numerical model}

The input parameters for our models are from Huitougou tunnel located in the northeast of China. The data mainly come from Yufu [23]. Huitougou tunnel is in the northwest of Changbai Mountain in the northeast of China. Even though we parametrize our model based on conditions in Changbai Mountain, there are many tunnels in cold regions with similar conditions in Canada, Norway, Japan, and Russia (see Tan et al. [24] for more information). In the Changbai Mountain some of the tunnels are not practically used for up to 8 to 9 months of a year due to frozen damage. The elevation of the tunnel is $814-930 \mathrm{~m}$. The mean temperature in winter (November to January) is $\sim-20^{\circ} \mathrm{C}$. The maximum temperature occurs in July and is $\sim 30^{\circ} \mathrm{C}$. The annual average temperature is $\sim 5^{\circ} \mathrm{C}$. According to geological investigation and the rock mechanical test, the surrounding rock of Huitougou tunnel is of grade V, using JTG classification [25]. We consider temperature conditions that often occur in cold regions. Therefore, we expect that our results presented in this work have some broad implications in understanding temperature field in other regions worldwide. Main input parameters (material properties) are presented in Table 1. Importantly, the surrounding rock has the highest thermal conductivity and specific heat capacity. The insulation layer has the lowest thermal conductivity to be able to block temperature migration into surrounding rocks. Here, we will quantify the heat migration depth into surrounding rocks with and without placing this low conductivity layer.

\section{Numerical results}

We study the tunnel temperature field in two different conditions with relatively low and high ambient temperature of $-20^{\circ} \mathrm{C}$ and $30^{\circ} \mathrm{C}$ representing winter and summer conditions of northeast China. Using different types of insulation layer and lining are common practice in cold regions. 
Here to better understand how using an insulation layer control temperature penetration (from ambient air in the tunnel) into the surrounding rocks, we performed additional simulations by placing insulation layer in the tunnel (see the discussion by Tan et al. [24] on different material used as insulation layer). Specifically, we look at the temperature field distribution of a tunnel, lining, and surrounding rock. Chosen boundary conditions representing conditions of Huitougou tunnel are shown in Fig. 2. As per Takumi et al. [12], we assume temperature deep into the surrounding rock are not affected by the ambient temperature and is equal to $5^{\circ} \mathrm{C}$. We defined the boundary conditions of the left and right boundaries as perfectly insulated with heat flow of $0 \mathrm{w}$. Similar to Lai et al. [3], air in the tunnel and the environment exchange heat convectively with a convection index of $15 \mathrm{~W} / \mathrm{m}^{2}{ }^{\circ} \mathrm{C}$. We set the top boundary temperature of $0^{\circ}$ and $15^{\circ} \mathrm{C}$ for winter and summer, respectively. This is consistent with prior work studying temperature field in cold regions (see Tan et al. [24]).

\subsection{Temperature results without insulation layer}

In this section, we present the temperature distribution results with no insulation layer placed in our model (see location of the insulation layer in Fig. 1b). Our simulation results are shown in Fig. 3. It is clear that the air temperature in the tunnel is the same as the ambient temperature $\left(-20^{\circ} \mathrm{C}\right.$ for winter and $30^{\circ} \mathrm{C}$ for summer) near the tunnel entrance. The temperature of lining and surrounding rock is affected by the ambient temperature. The temperature gradually transfers to the surrounding rock with initial temperature of $5^{\circ} \mathrm{C}$ ). In winter, an average freezing depth is $\sim 5 \mathrm{~m}$ from the lining surface. This is in consistent with Takumi et al. [12] findings where they developed a theoretical equation for estimating the temperature in the tunnel.

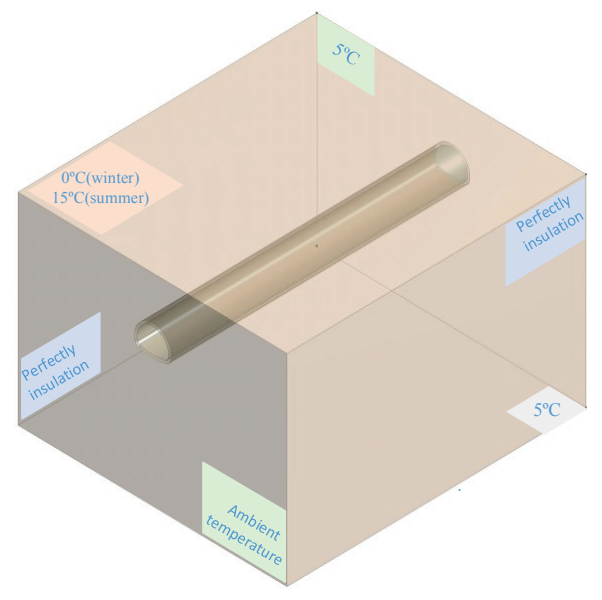

Fig. 2 Boundary conditions $\mathbf{a}$
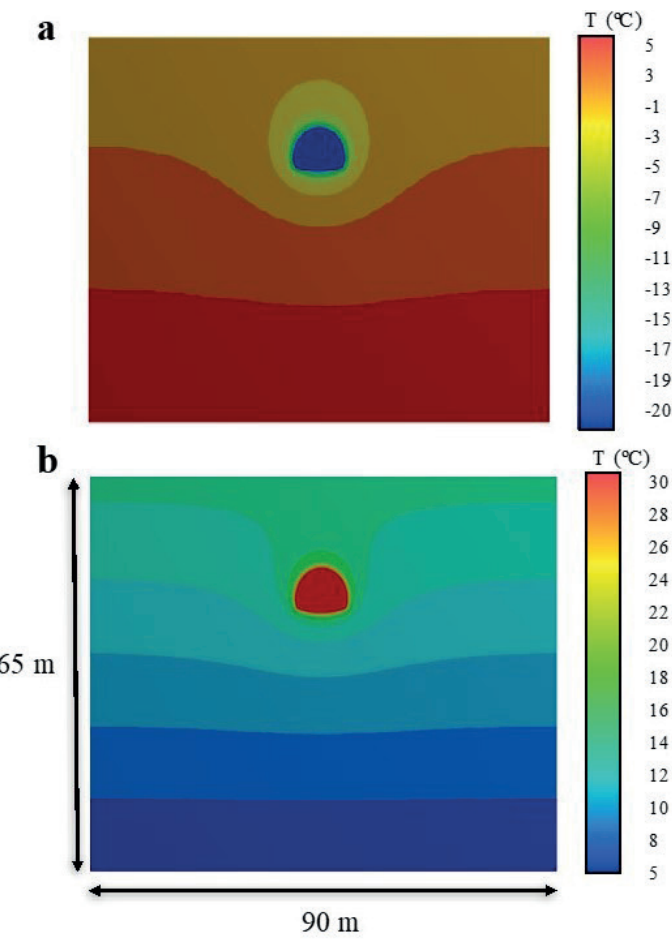

Fig. 3 Cross-section of temperature distribution without insulation layer for (a) winter condition and (b) summer condition

a
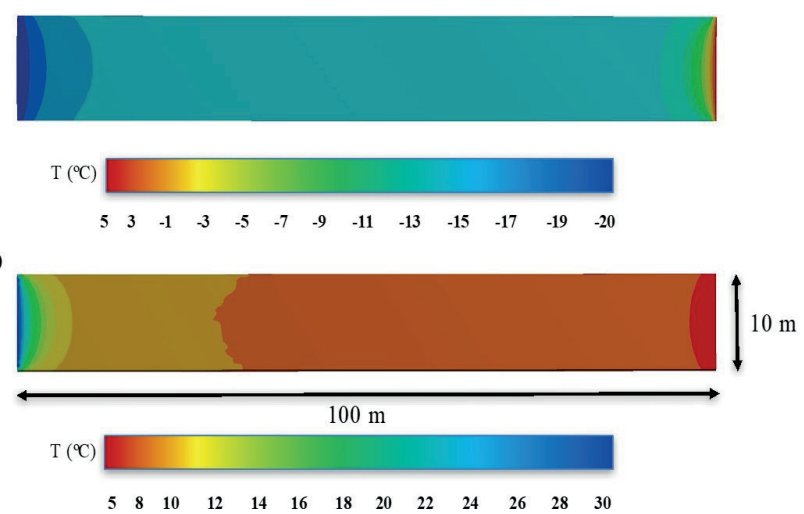

Fig. 4 Temperature distribution in the tunnel without insulation layer for (a) winter condition, and (b) summer condition. The left side of the domain corresponds to the tunnel entrance

Additionally, the temperature distribution within the tunnel itself is shown in Fig. 4. It is clear that the tunnel entrance temperature has limited effect on the section deep inside the tunnel, which temperature still maintains $5^{\circ} \mathrm{C}$. In winter, the temperature of tunnel portal is affected by ambient temperature and drops to $-20^{\circ} \mathrm{C}$. The temperature of the air rises gradually along the tunnel. In summer, the temperature of tunnel portal is affected by ambient temperature, and it rises to $30^{\circ} \mathrm{C}$. The temperature drops gradually along the tunnel. It is clear that both in winter and summer the temperature deep in the tunnel stays constant due to insulation boundary condition used. 


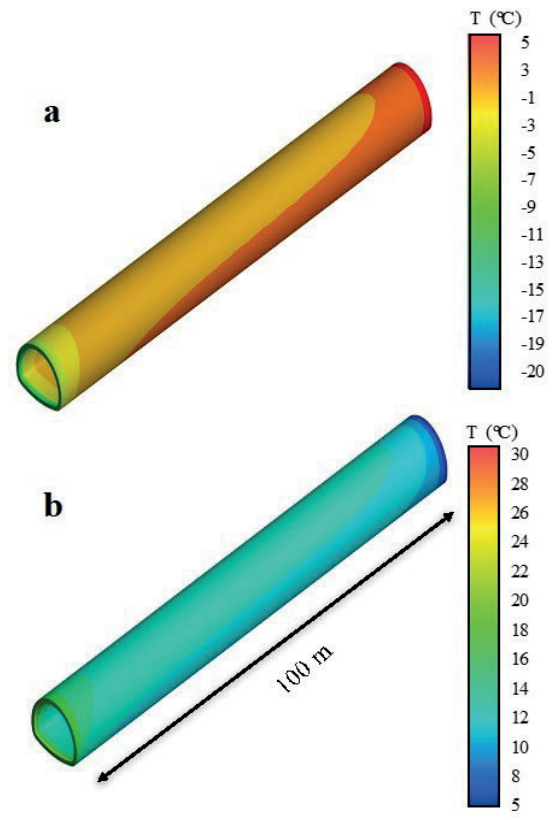

Fig. 5 Temperature distribution of tunnel lining without insulation layer in (a) winter, and (b) summer. The left side of the domain corresponds to the tunnel entrance

a
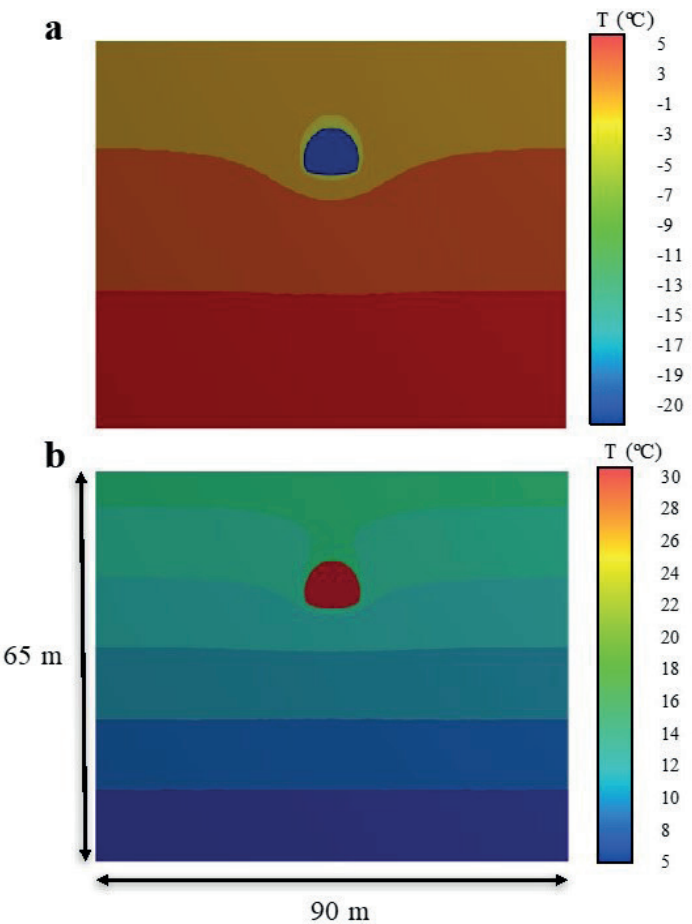

Fig. 6 Cross-section of temperature distribution with insulation layer for (a) winter condition and (b) summer condition

The temperature distribution of the tunnel lining is shown in Fig. 5, from which we can see that in winter the temperature of the lining near the tunnel entrance is close to the ambient temperature, which reaches $-20^{\circ} \mathrm{C}$. As we move through the tunnel, the temperature gradually increases and stabilizes to $5^{\circ} \mathrm{C}$. In summer, the temperature of the lining near the tunnel portal is close to the ambient temperature and reaches $30^{\circ} \mathrm{C}$, and as we move through the tunnel, the temperature gradually drops and stabilizes to $5^{\circ} \mathrm{C}$. Overall, nearly full length of the lining (mainly the top part) is affected by ambient temperature.

\subsection{Temperature results with insulation layer}

In this section, we show how placing an insulation layer between the tunnel lining and the air affects the temperature distribution. As mentioned, the insulation layer thickness is only $5 \mathrm{~cm}$, similar to what was suggested by Feng et al. [26]. We expect that the insulation layer hinders the temperature to migrate into surrounding rocks. Our numerical modeling results for temperature distribution is shown in Fig. 6.

As shown in Fig. 6, the insulation layer seems to be effective in keeping the surrounding rock's temperature at $5^{\circ} \mathrm{C}$ due to its low thermal conductivity. In winter, even though the tunnel air temperature is $-20^{\circ} \mathrm{C}$, the temperature outside the insulation layer is still above zero, and there is no freezing effect. This is not true when an insulation layer is not used (see Fig. 3a). In summer, the temperature is $14^{\circ} \mathrm{C}$ near the lining outside the insulation layer, which is less than the ambient temperature. As shown, the insulation layer acts effectively in moderating temperature migration into surrounding rocks. Using the insulation layer could potentially decrease freezing damage to the surrounding rocks to some extent.

The temperature distribution of lining is shown in Fig. 7. Comparing Figs. 5 and 7 reveals that the temperature distribution of lining is different in two conditions with and without insulation layer. This is more obvious near the entrance where the temperate is much closer to ambient temperature when there is no insulation layer (Fig. 5). Overall, when the insulation layer is used, the temperature of the lining is above zero. Therefore, the lining is unlikely to be frozen in winter. The practical implication is that the insulation layer is essential for tunnels built in cold regions. To make this conclusion clear, we present the temperature distribution of the surrounding rock along the radial direction in Fig 8. The temperature of the surrounding rock with insulation layer is close to the air temperature $\left(-20^{\circ} \mathrm{C}\right.$ in winter and $30^{\circ} \mathrm{C}$ in summer). In winter, the temperature without insulation layer near the lining is $-4.4^{\circ} \mathrm{C}$. However, when insulation layer is used the temperature is close to zero. In summer, the temperature of the surrounding rock without insulation is $17^{\circ} \mathrm{C}$, whereas the temperature with insulation is about $14^{\circ} \mathrm{C}$. As we move 


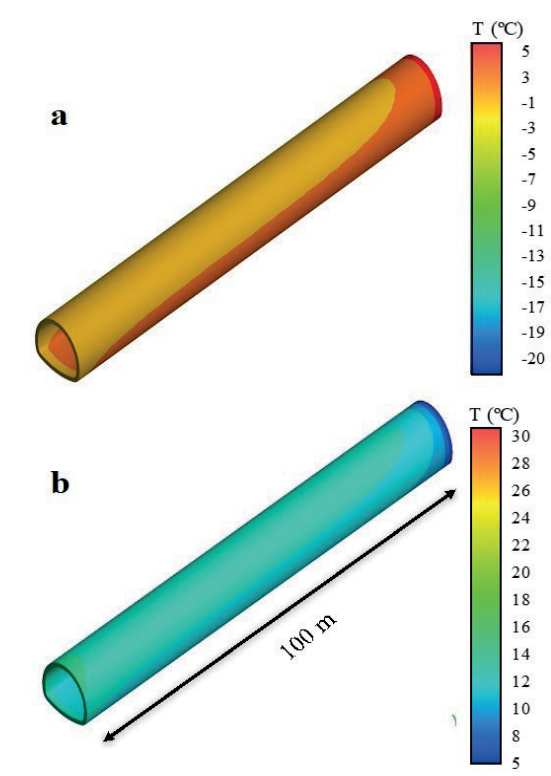

Fig. 7 Temperature distribution of tunnel surrounding rock with insulation layer in (a) winter, and in (b) summer. The left side of the domain corresponds to the tunnel entrance

away from the tunnel itself, the temperature remains the same for both cases with and without the insulation layer. At depth of $\sim 20 \mathrm{~m}$, the surrounding rock has the same temperature with and without insulation layer.

\section{Sensitivity to insulation layer parameters}

In this section, we perform sensitivity analysis to better understand the potential effects of heat transport parameters of the insulation layer on temperature of surrounding rock. The parameters include thermal conductivity, and thickness of the insulation layer. We found that specific heat capacity and density have no significant effects on temperature migration into surrounding rocks using conditions of Changbai Mountain. Therefore, we only show our sensitivity results for thermal conductivity and thickness. To perform the sensitivity, we only focus on winter condition with the ambient temperature of $-20^{\circ} \mathrm{C}$.

\subsection{Thermal conductivity}

Thermal conductivity is one of the most important parameters affecting heat transport. We chose the thermal conductivity of insulation layer as $0.005,0.01,0.02,0.04$, and $0.06 \mathrm{~W} / \mathrm{m}^{\circ}{ }^{\circ} \mathrm{C}$. Note that the results presented in previous section were for thermal conductivity of $0.02 \mathrm{~W} / \mathrm{m} \cdot{ }^{\circ} \mathrm{C}$. In order to compare the temperature distribution in the surrounding rock, we looked at temperature distribution along the radial direction. The temperature of surrounding rock along the radial direction is as Fig. 9.
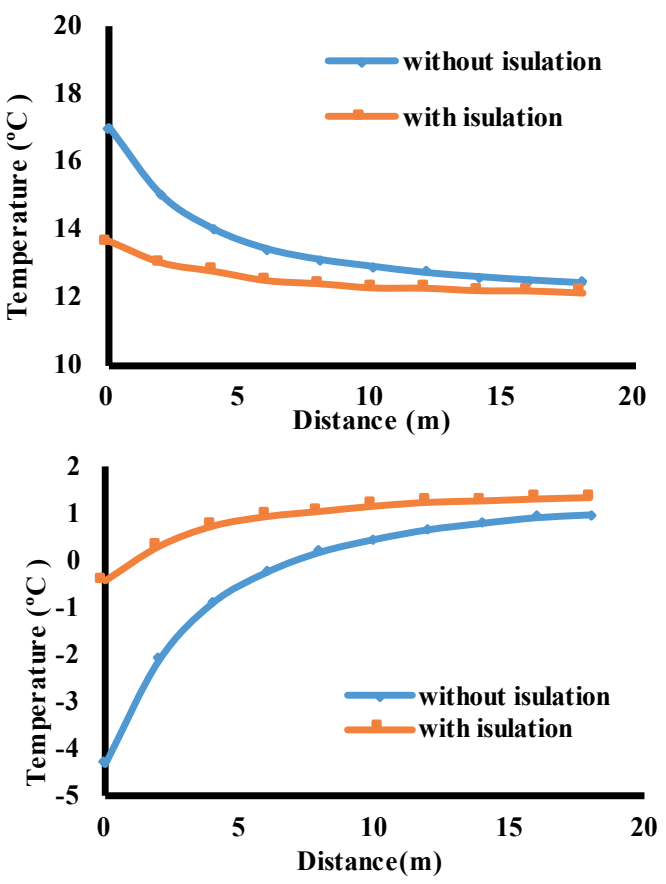

Fig. 8 Temperature distribution of surrounding rock along the radial direction in (top) summer, and (bottom) winter

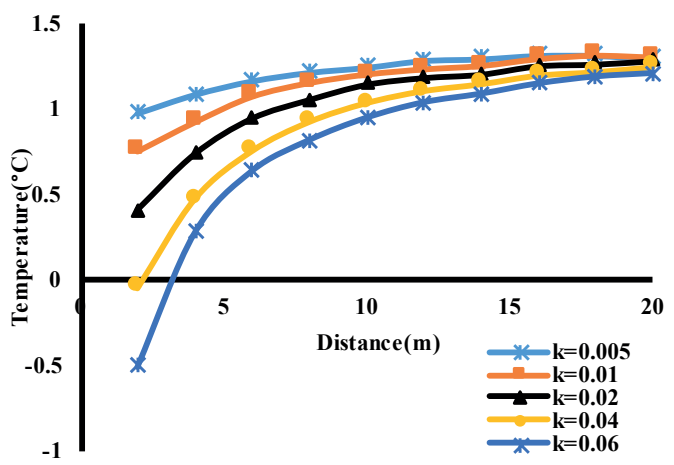

Fig. 9 The temperature versus distance from the tunnel for different values of insulation layer thermal conductivity. Using smaller values of thermal conductivity result in smaller temperature migration in to surrounding rocks

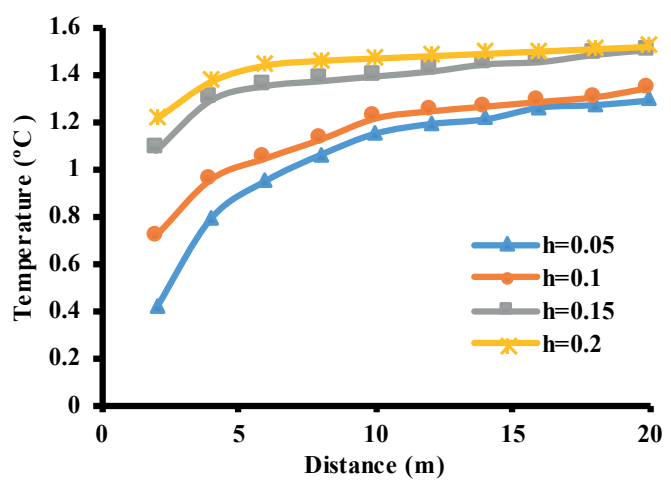

Fig. 10 The temperature versus distance from the tunnel for different values of insulation layer thickness 
As shown in Fig 9, increasing the thermal conductivity results in a larger variability in temperature in surrounding rocks. When the thermal conductivity is 0.005 $\mathrm{W} / \mathrm{m} \cdot{ }^{\circ} \mathrm{C}$, the temperature difference in surrounding rock and near the lining is $\sim 1^{\circ} \mathrm{C}$, and the affected distance is nearly 25 percent shorter than the case with thermal conductivity is $0.06 \mathrm{~W} / \mathrm{m} \cdot{ }^{\circ} \mathrm{C}$, in which the temperature of surrounding rock near the lining is $\sim-0.5^{\circ} \mathrm{C}$. It is worth noting that there is no significant difference in temperature at distance of $20 \mathrm{~m}$ away from tunnel, for any values of thermal conductivity.

\subsection{Insulation layer thickness}

The insulation layer thickness is the second important factor that affects the heat transport to surrounding rocks. We chose thickness of $0.05,0.1,0.15$, and $0.2 \mathrm{~m}$. Note that the results presented in previous section were for thickness of $0.05 \mathrm{~m}$. Results of temperature in surrounding rock along the radial direction are as Fig. 10.

Fig. 10 shows how changing the insulation layer thickness affects the temperature distribution. The more is the thickness of the insulation, the less is the heat migration into surrounding rocks. When the thickness is $0.05 \mathrm{~m}$, the temperature of surrounding rock near the lining is $0.4^{\circ} \mathrm{C}$. When the thickness changes to $0.2 \mathrm{~m}$, the temperature of surrounding rock near the lining is $1.2^{\circ} \mathrm{C}$.

\section{Conclusions}

In this paper, we numerically analyzed the temperature field within a tunnel and surrounding rock. The temperature field within the tunnel, its lining, and the surrounding rock under the typical winter ambient temperature $\left(-20^{\circ} \mathrm{C}\right)$ and the summer ambient temperature $\left(30^{\circ} \mathrm{C}\right)$ in cold regions area were analyzed. Specifically, we parametrize our model based on data from Huitougou tunnel in Changbai Mountain of northeast China. We also studied the potential influence of insulation layer on the temperature migration into the tunnel lining and of surrounding rock. Additionally, we performed sensitivity simulations to better understand how thermal conductivity, thickness of the insulation layer, heat capacity and density of the insulation layer control on temperature migration into surrounding rocks. We found that (1) insulation layer is important in hindering ambient temperature migration into surrounding rocks; (2) depth of $\sim 20 \mathrm{~m}$ is the maximum depth affected by ambient temperature; (3) there is no significant effects from heat capacity and density of the insulation layer; however, both smaller thermal conductivity and higher thickness of the insulation layer could decrease the maximum temperature penetration depth into surrounding rocks; (4) surrounding rocks located close to tunnel entrance are more sensitive areas to ambient temperature variation. Therefore, we recommend using thicker insulation layer with smaller thermal conductivity for areas close to the tunnel entrance. Future work could consider transient heat transport simulations, incorporate surrounding rock heterogeneity, and study different boundary conditions among others.

\section{Acknowledgement}

This work has been funded by Engineering Research Center of Geothermal Resources Development Technology and Equipment of Ministry of Education, Jilin University. Z. Dai thanks Jilin University for the start-up funding and the National Natural Science Foundation of China [Grant numbers: 41772253] supporting this work.

\section{References}

[1] Feng, Q., Liu W.-W., Jiang, B.-S. "Analytical Solution for the Stress and Deformation of Rock Surrounding a Cold-regional Tunnel under Unequal Compression", Cold Regions Science and Technology, 139, pp. 1-10, 2017. https://doi.org/10.1016/j.coldregions.2017.04.003

[2] Lai, Y., Yu, W., Wu, Z., He, P., Zhang, M. "Approximate Analytical Solution for the Temperature Fields of a Circular Tunnel in Cold Regions" Journal of Glaciology and Geocryology, 23(2), pp. 126130, 2001.

[3] Lai, J. "Experimental Study on Air Temperature Field for ColdRegion Tunnel in Qinghai-Tibet Plateau: A Case Study", In: Advances in Computational Environment Science. Advances in Intelligent and Soft Computing, vol 142, Springer, Heidelberg, germany, pp. 265-271, 2012.

https://doi.org/10.1007/978-3-642-27957-7 33

[4] Chen, J. "Field Test and Analysis of Effect of Antifreeze Thermal Insulating Layer in Tiziling Tunnel", Highway, 8, pp. 226-229, 2006.

[5] Li, W., Wu, Y., Fu, H., Zhang, J. "Long-term Continuous in-situ Monitoring of Tunnel Lining Surface Temperature in Cold Region and its Application", International Journal of Heat and Technology, 33(2), pp. 39-44, 2015. https://doi.org/10.18280/ijht.330206

[6] Chen. J.-X., Luo., J.-B. "Changing Rules of Temperature Field for Tunnel in Cold Area", Journal of Traffic and Transportation Engineering, 8(2), pp. 44-48, 2008.

[7] Ryu, S. W., Park, J. Y., Kim, H. B., Lee, J., Cho, Y.-H. "Behavior and Performance Evaluation of a Concrete Pavement Considering the Temperature Condition in a Tunnel", International Journal of Highway Engineering, 18(2), pp. 11-18, 2016. https://doi.org/10.7855/IJHE.2016.18.2.011 
[8] Zhang, G., Xia, C., Yang, Y., Sun, M., Zou, Y. "Experimental Study on the Thermal Performance of Tunnel Lining Ground Heat Exchangers", Energy and Buildings, 77, pp. 149-157, 2014. https://doi.org/10.1016/j.enbuild.2014.03.043

[9] Sutoh, A., Mikami, T., Okada, M., Kawamura, T. "Periodic Change of Atmospheric Temperature at Tunnel in Cold Region", Proceedings of Tunnel Engineering, JSCE, 10, pp. 251-256, 2000. https://doi.org/10.11532/journalte1991.10.251

[10] Sutoh, A., Mikami, T., Okada, M. Kawamura, T., Iizuka, T. "Periodic Change of Temperature overall the length at Tunnel in Cold Region", Proceedings of Tunnel Engineering, JSCE, 11, pp. 9-14, 2001. https://doi.org/10.11532/journalte1991.11.9

[11] Sutoh, A., Mikami, T., Okada, M., Kaydoya, S. Kitahara, M. "Inspection of the Identified and Interpolated Temperatures at Tunnel for Heat Insulator Design", Journal of applied mechanics, 7, pp. 139-144, 2004.

https://doi.org/10.2208/journalam.7.139

[12] Takumi, K., Takashi, M., Kouichi, F. "An Estimation of Inner Temperatures at Cold Region Tunnel for Heat Insulator Design", Proceedings of Structural Engineering Symposium, pp. 32-38, 2008. https://doi.org/10.11532/structcivil.54A.32

[13] Lee, C. S., Kim, Y. H. "An Estimation of the Temperature-dependent Thermal Conductivity for Hybrid-fiber Reinforced Shield Tunnel Lining", Journal of the Korea Institute for Structural Maintenance and Inspection, 16(4), pp. 99-106, 2012. https://doi.org/10.11112/jksmi.2012.16.4.099

[14] Luo, Y., Chen, J., Wang, M. "Calculation Method of Tunnel Portal Temperature Based on Spatial Interpolation Theory", China Railway Science, 31, pp. 42-45, 2010.

[15] Wang, T., Zhou, G., Wang, J., Zhao, X. "Stochastic Analysis for the Uncertain Temperature Field of Tunnel in Cold Regions", Tunnelling and Underground Space Technology, 59, pp. 7-15. 2016. https://doi.org/10.1016/j.tust.2016.06.009

[16] Nguyen, H. T., Wong, H., Fabbri, A., Georgin, J. F., Prud'homme, E. "Analytical Study of Freezing Behavior of a Cavity in Thermo-poroelastic Medium", Computers and Geotechnics, 67, pp. 33-45, 2015. https://doi.org/10.1016/j.compgeo.2015.02.006

[17] Lai, Y., Wang, Q., Niu, F., Zhang, K. "Three-dimensional Nonlinear Analysis for Temperature Characteristic of Ventilated Embankment in Permafrost Regions", Cold Regions Science and Technology, 38(2-3), pp. 165-184, 2004.

https://doi.org/10.1016/j.coldregions.2003.10.006

[18] Tan, X., Chen, W., Wu, G., Yang, J. "Numerical Simulations of Heat Transfer with Ice-water Phase Change Occurring in Porous Media and Application to a Cold-region Tunnel", Tunnelling and Underground Space Technology, 38, pp. 170-179, 2013. https://doi.org/10.1016/j.tust.2013.07.008

[19] Tan, X. J., Chu, Y. D., Chen, W. Z., Dai, Y.-H., Chen, P.-S. "A New Method to Study Thermal Conductivity of Geomaterials Considering Phase Change", Rock and Soil Mechanics, 31(2), pp. 70-74, 2010.

[20] Lai, J. X., Fan, H. B., Dong, W. W., Liu, Q. "Numerical Investigation of the Temperature Field of Freeze-proof Separate Lining in a Coldregion Tunnel", Jordan Journal of Civil Engineering, 9(4), pp. 499511, 2015.

https://doi.org/10.12816/0023870
[21] Zhou, X., Zeng, Y., Fan, L. "Temperature Field Analysis of a Coldregion Railway Tunnel Considering Mechanical and Train-induced Ventilation Effects", Applied Thermal Engineering, 100, pp. 114124, 2016.

https://doi.org/10.1016/j.applthermaleng.2016.01.070

[22] Li, S., Niu, F., Lai, Y., Pei, W., Yu, W. "Optimal Design of Thermal Insulation Layer of a Tunnel in Permafrost Regions Based on Coupled Heat-water Simulation", Applied Thermal Engineering, 110, pp. 1264-1273, 2017.

https://doi.org/10.1016/j.applthermaleng.2016.09.033

[23] Wang, Y. F. "Research on the Temperature Field of Tunnel Built in Cold Area", Master, Chang'an University, 2006. (in Chinese)

[24] Tan, X., Chen, W., Yang, D., Dai, Y., Wu, G., Yang, J., Yu, H., Tian, H., Zhao, W. "Study on the influence of airflow on the temperature of the surrounding rock in a cold region tunnel and its application to insulation layer design", Applied Thermal Engineering, 67(1-2), pp. 320-334, 2014. https://doi.org/10.1016/j.applthermaleng.2014.03.016

[25] The Ministry of Communications of P. R. China. "Specifcations for Design of Highway Tunnels (JTG D70/2-2014)", People's Communications Press, Beijing, 2014. (in Chinese)

[26] Feng, Q., Jiang, B.-S., Zhang, Q., Wang, G. "Reliability Research on the 5-cm-thick Insulation Layer Used in the Yuximolegai Tunnel Based on a Physical Model Test", Cold Regions Science and Technology, 124, pp. 54-66, 2016. https://doi.org/10.1016/j.coldregions.2016.01.001 